Article

\title{
Robust Scheduling Optimization Model for Multi-Energy Interdependent System Based on Energy Storage Technology and Ground-Source Heat Pump
}

\author{
Zhongfu Tan, Hongwu Guo, Hongyu Lin, Qingkun Tan *(D), Shenbo Yang, De Gejirifu, Liwei Ju \\ and Xueying Song \\ School of Economics and Management, North China Electric Power University, Beijing 102206, China; \\ tzhf@ncepu.edu.cn (Z.T.); 1162106024@ncepu.edu.cn (H.G.); hone@ncepu.edu.cn (H.L.);

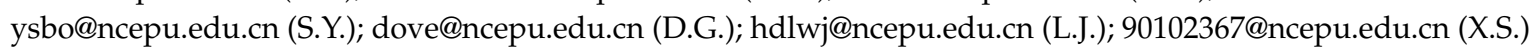 \\ * Correspondence: tanqingkun@ncepu.edu.cn; Tel.: +86-181-0103-9610
}

Received: 6 November 2018; Accepted: 30 December 2018; Published: 8 January 2019

\begin{abstract}
The energy consumed by buildings makes up a significant part of total social energy consumption. The energy use rate of the traditional cooling and heating unit is low. A distributed cooling, heating, and power (CHP) system can achieve cascade use of energy and reduce the long-distance transportation of energy. Along with the wide use of ground-source heat pumps and energy storage technology, the combined cooling, heating, and power (CCHP) system coupled with a ground-source heat pump and energy storage technology is increasingly being used. Firstly, we proposed the construction of a CCHP system driven by distributed energy resources (DERs) including three subsystems of an electricity subsystem, a CCHP subsystem and an auxiliary heating subsystem as the object of study in this paper. Besides, with the goals of reducing carbon emissions, increasing energy efficiency, and minimizing system cost, a constraint mechanism based on the DOM-PSO (dynamic object method/particle swarm optimization) algorithm was applied. Finally, taking Tianjin Eco-City as an example, we used the PSO algorithm to analyze the operating characteristics of the cold and power cogeneration system under the uncertainty of the wind power output. The simulation results show that the joint optimization mode operation strategy can balance the results of different optimization modes by increasing the robust coefficient of wind power. Of all scenarios examined, the CCHP system coupled with the ground-source heat pump and energy storage technology performed best.
\end{abstract}

Keywords: ground-source heat pump; energy storage; robust scheduling optimization; distributed energy; PSO algorithm

\section{Introduction}

With the progress of society and the improvement of people's living standards, China's demand for energy is increasing rapidly: the resulting imbalance between the supply and demand of energy production and consumption is increasing, while the coal-based energy structure is having a serious impact on the environment. The security of energy supply restricts the development of China's economy. Gas cooling and thermoelectricity are distributed energy sources, which can achieve energy savings, emission reduction, and energy structure optimization, and they have been applied to many projects. A combined cooling, heating, and power (CCHP) system has many advantages, for example, it is energy-efficient, which leads to energy savings; it is clean, which is compatible with environmental protection goals; it is a reliable energy supply, and so on. For these reasons, CCHP system is developing 
rapidly in many countries [1,2]. In reference [3], a CCHP system including a power generation unit, absorption refrigeration equipment, electric refrigeration equipment, and heating equipment was built, enabling the hourly cooling, heating, and power load demand to be met in various buildings. In reference [4], the authors considered the mismatch of thermoelectric load and the problem of energy mutual conversion between thermoelectric and other forms of energy. The authors of references $[5,6]$ combined intermittent power with the CCHP system, and the conclusion is that the randomness of the unit output and thermoelectric load have an important impact on the economy of the system. In reference [7], the factor of electricity price was considered in a model of CCHP system optimization, and the effects of different fixed electricity prices on the economy of the system were simulated. The authors of references $[8,9]$ studied the economic efficiency of a CCHP system under the condition of peak-valley electricity prices.

Reference [10] studied the performance and pollutant emission characteristics of a power (CHP) and CCHP system under different climatic conditions. Reference [11] analyzed the performance of the CCHP system based on the users' energy demands. Reference [12] studied a CCHP system with the supercritical carbon dioxide cycle and solar energy as the driving heat source was studied. In reference [13], a system of solar and fuel cells improved the efficiency of a CCHP system. The authors of reference [14] proposed a multi-objective optimization model for CCHP system and optimized the operation strategy under different climate conditions. In reference [15], thermal economics was used to optimize the CCHP system of a building. In reference [16], a CCHP system was studied in terms of energy management and operation optimization. In reference [17], a hybrid nonlinear model was used to evaluate the performance of a CCHP system. The authors of reference [18] evaluated the feasibility of a project that planned a CCHP system driven by renewable energy on a remote island. In references [19,20], a simple and effective economic scheduling strategy was adopted to reduce the cost of a CCHP system. Their results show that the economic dispatch strategy can reduce the total cost of the system, including the initial investment and operating cost. In references [21,22], a multi-objective optimization (MOO) approach was proposed to perform a system wide analysis of public hospital resources and railway capacity. The MOO approach was extensively tested on a case study and its significant worth was shown. In this MOO approach, the epsilon constraint method (ECM) was used.

Based on the above analysis, we can see that the existing literature contains abundant researches on CCHP operations. However, some problems still exist: while the driving energies of the studied CCHP systems include natural gas (NG), solar energy, biomass, and ground-source heat pump (GSHP) systems, there are few studies that discuss a CCHP system driven by wind energy and GSHPs. Other studies have constructed performance indexes from all aspects of CCHP systems driven by NG, but they limit the applicability of these performance indexes. based on the above-mentioned analysis, the contribution of this paper are as follows.

A combined cooling, heating, and power system driven by wind power, includes three subsystems: an electricity subsystem, CCHP subsystem, and auxiliary heating subsystem. The electricity subsystem consists of a wind power plant and gas turbines. The CCHP subsystem consists of a heat recovery steam generator, steam turbines, a compression chiller, an absorption chiller, a heat exchanger, and a ground-source heat pump. The auxiliary heating subsystem consists of solar heater collectors, a thermal storage tank, and a regenerative electric boiler.

A multi-objective operation optimization model and solution methodology for the CCHP system based on thermal energy storage and a ground-source heat pump were proposed. Performance index system was constructed from three aspects: energy performance, economic performance, and environmental performance.

In the second stage of the study, the construction of Tianjin Eco-City was taken as the simulation object for analyzing the advantages of a CCHP system based on thermal energy storage and a ground-source heat pump with different robust coefficients.

The rest of the paper were organized as follows. Section 2 described the main structure of the CCHP system based on thermal energy storage and a ground-source heat pump, including the 
electricity subsystem, thermal energy storage, the ground-source heat pump subsystem, and the auxiliary heating subsystem. Section 3 defined the operation strategy of the CCHP system based on thermal energy storage and a ground-source heat pump and establishes performance indexes. Section 4 put forward a multi-objective operation optimization model and solution methodology for the CCHP system based on thermal energy storage and a ground-source heat pump. Section 5 took the Tianjin Eco-City as the simulation object and analyzed the advantages of the CCHP system based on thermal energy storage and a ground-source heat pump. Section 6 demonstrated the highlights and main conclusions of this paper.

\section{Description of the CCHP System Based on Thermal Energy Storage and Ground-Source Heat Pump}

A ground-source heat pump uses shallow-layer geothermal resources from the earth's surface as the cold and heat sources. The CCHP system is driven by distributed energy resources and consists of three subsystems, namely, the electricity subsystem, the CCHP subsystem, and the auxiliary subsystem. Figure 1 illustrates the energy flow diagram of the CCHP system based on thermal energy storage and a ground-source heat pump.

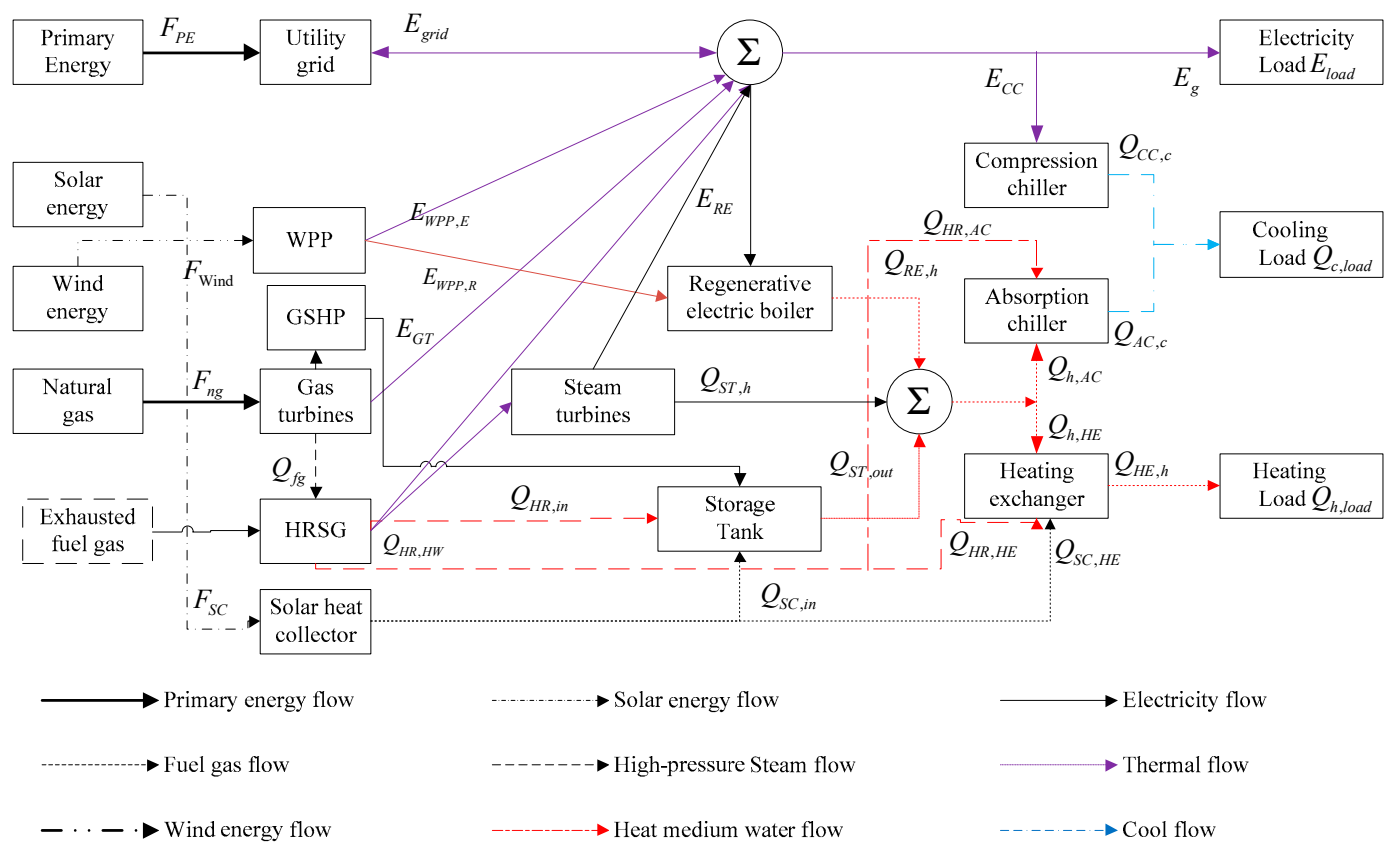

Figure 1. Combined cooling, heating, and power (CCHP) system based on thermal energy storage and ground-source heat pump. WPP: wind power plant; GSHP: ground-source heat pump; HRSG: heat recovery steam generators.

In this study, the CCHP system consists of a gas generator set, solar heater, wind turbine, absorption heat pump unit, GSHP unit, electric refrigeration steam compression refrigeration unit, and related auxiliary equipment. The electrical load is provided by the grid, a gas turbine, and wind power; the cooling load is provided by the absorption heat pump unit, GSHP unit, storage tank, and electric refrigeration vapor compression refrigeration unit; the heating load is provided by the absorption heat pump unit, GSHP unit, and storage tank.

\section{Operation Performance Evaluation Indexes}

\subsection{Operation Strategy}

The operation strategy of the CCHP system based on thermal energy storage and a ground-source heat pump is as follows. 
NG enters the gas generating set to produce electrical energy $\left(E_{P G U}\right)$ and to drive the absorption heat pump units $\left(E_{A M}\right)$, GSHP units, energy storage tank, and auxiliary equipment. The power for the electric refrigeration vapor compression refrigeration unit and GSHP unit is supplied by a gas combustion generator, a wind turbine, or the grid. When the power generation capacity of the CCHP system is insufficient, the system can buy electricity from the public grid. On the other hand, when the CCHP system has a surplus of power generation capacity, it can sell electricity to the public grid.

The GSHP unit operates throughout the year, and the cooling tower is set to adjust the peak value of the heat release of the GSHP unit. During a period when the low valley electricity price is carried out, the GSHP unit stores the energy in the storage tank $\left(Q_{S T, h}\right)$ under cooling conditions and stores the heat in the storage tank $\left(Q_{S T, h}\right)$ under heating conditions.

Under the system refrigerating conditions, high-temperature smoke from a group of motors and high-temperature cylinder water enter the absorption heat pump as the heat source for refrigeration. The shortage of cooling capacity is partly due to the energy storage tank cold storage stored at valley price $\left(Q_{S T, c}\right)$, the GSHP unit $\left(Q_{G S H P, c}\right)$, and the electric refrigeration steam compression refrigeration unit $\left(Q_{E C}\right)$.

Under system heating conditions, the smoke from the group of motors $\left(Q_{R}\right)$ enters the absorption heating pump, the cylinder jacket water enters the heat exchanger, and they both supply heat (thermal load). The rest of heat demand is satisfied by the storage tank and GSHP.

\subsection{Performance Indexes}

The CCHP system based on thermal energy storage and a ground-source heat pump uses wind, solar energy, and the GSHP satisfies the system's cooling, heating, and electrical load demand. The consumption of natural gas can be reduced, in which case energy savings and emission reduction can be achieved. As the cost of the system is relatively high, the CCHP system based on thermal energy storage and a ground-source heat pump should be evaluated from three aspects: energy, economic, and environmental performance.

\subsubsection{Energy Performance Indexes}

(1) Operation efficiency of a gas system

For the reference CCHP system, the energy rate can be calculated by Equation (1):

$$
E R^{R E}=\frac{Q_{h, \text { load }}+Q_{c, \text { load }}+E_{\text {load }}}{F_{n g}^{R E}}
$$

wherein $E R^{R E}$ is the energy rate of the system, and $F_{n g}^{R E}$ is the natural gas input to the system.

(2) Renewable energy operation efficiency

Wind and solar energy are renewable energy sources, and the NG saving rate (NSR) is used to evaluate the system's wind and solar absorptive capacity. The NSR is calculated by Equation (2).

$$
\mathrm{NSR}=\frac{F_{n g}^{R E}-F_{n g}}{F_{n g}^{R E}}
$$

(3) System operation efficiency

The energy rate (ER) of the GSHP CCHP system can be calculated by Equation (3):

$$
\mathrm{ER}=\frac{Q_{h, \text { load }}+Q_{c, \text { load }}+E_{\text {load }}}{F_{n g}+F_{W P P}+F_{\text {Solar }}+F_{G S H P}}
$$


wherein $Q_{h, \text { load }}, Q_{c, \text { load }}$, and $E_{\text {load }}$ are the system load of heating, cooling, and power, respectively; $F_{n g}, F_{W P P}, F_{S o l a r}$, and $F_{G S H P}$ are the inputs of natural gas, wind power plant (WPP), solar energy, and ground-source heat pump.

\subsubsection{Economic Performance Indexes}

For the CCHP system based on thermal energy storage and a ground-source heat pump, the economic performance is divided into three aspects: the system operating cost, the net present value (NPV), and the internal rate of return (IRR).

(1) The operating cost

For the CCHP system, the total operating cost (TOC) consists of the power purchase cost, gas consumption cost, and other operating costs. TOC is calculated as

$$
\mathrm{TOC}=E_{b u y} \cdot p_{e l, b u y}-\left(E_{e l, \exp \text { ort }}^{W P P} \cdot p_{e l, \text { exp ort }}^{W P P}+E_{e l, \exp \text { ort }}^{G T} \cdot p_{e l, \text { exp ort }}^{G T}\right)+F_{G T} \cdot p_{N G}+\text { Cost }_{\text {oth }}
$$

wherein $E_{b u y}$ is the system electricity purchased from the grid, and $p_{e l, b u y}$ is the price of the system electricity purchased from the grid. $p_{\text {el,exp ort }}^{W P P}, p_{\text {el, } \text {,export }}^{G T}$ are the prices of wind power and gas generation; $F_{G T}$ is the natural gas consumption; $p_{N G}$ is the price of natural gas; $\operatorname{Cost}_{\text {oth }}$ represents other operating costs.

(2) The net present value

The CCHP system based on thermal energy storage and a ground-source heat pump can yield benefits by reducing operating costs, but the investment of the Wind Power Plant (WPP) and photovoltaic (PV) may be higher than gas turbine (GT), which will increase the total investment cost of the system. Here, we introduce the NPV method which is calculated by Equation (5):

$$
\mathrm{NPV}=\sum_{j=1}^{J} \frac{(1-i)^{j}-1}{i(1-i)^{j}} C S_{j}-\left(I_{R E}^{0}-I^{0}\right)
$$

wherein $i$ is the discount rate; $j$ is the index for the period of operation; $J$ is the total number of years in operation; $I_{R E}^{0}$ and $I^{0}$ are the initial investment costs of the reference system. If NPV $\geq 0$, it means that the system's investment effect is beneficial. Otherwise, it is not.

(3) The IRR

The IRR indicates the expected rate of return on project investment. IRR can be calculated by Equation (6).

$$
\sum_{j=1}^{J} \frac{(1-I R R)^{j}-1}{I R R(1-I R R)^{j}} C S_{j}-\left(I_{R E}^{0}-I^{0}\right)=0
$$

wherein $C S_{j}$ is the system's total operating cost in scenario $j$.

\subsubsection{Environmental Performance Indexes}

To evaluate the system's environmental performance, carbon emission (CE) can be determined by Equation (7)

$$
\mathrm{CE}=\gamma_{n g} F_{n g}+\varphi E_{b u y}
$$

wherein CE is the carbon emission of the CCHP system; $\gamma_{n g}$ is the carbon dioxide emission from natural gas combustion; $\varphi$ is the carbon dioxide emissions per unit power; $E_{b u y}$ is the system electricity purchased from the grid. 


\section{Multi-Objective Operation Optimization Model}

In this section, the performance evaluation indexes of the system operation are evaluated to determine the optimal performance of the operation, optimizing the operation strategy of the CCHP system. Therefore, we choose ER, TOC, and CE as the optimization objectives.

\subsection{Objective Functions}

For the GSHP CCHP system, a higher ER means better energy use efficiency as a measure of the energy performance, A lower TOC means a lower operating cost as a measure of the economic performance, and a lower CE means lower carbon dioxide emissions as a measure of the environmental performance. The detailed objective functions are as follows:

$$
\begin{gathered}
f_{1}=\mathrm{ER}=\max \left\{\frac{\sum_{t=1}^{T}\left[Q_{h, \text { load }}(t)+Q_{c, \text { load }}(t)+E_{\text {load }}(t)\right]}{\sum_{t=1}^{T}\left[F_{G T}(t)+F_{W P P}(t)+F_{\text {Solar }}(t)+F_{G S H P}(t)\right]}\right\} \\
f_{2}=\mathrm{TOC}=\min \sum_{t=1}^{T}\left\{E_{b u y}(t) \cdot p_{\text {el, buy }}-\left(\begin{array}{c}
E_{\text {el, exp ort }}^{W P P}(t) \cdot p_{\text {el,exp ort }}^{W P P} \\
+E_{\text {el, exp ort }}^{G T}(t) \cdot p_{\text {el,exp ort }}^{G T}
\end{array}\right)+F_{G T}(t) \cdot p_{N G}+\text { Cost }_{\text {oth }}\right\} \\
f_{3}=\mathrm{CE}=\min \sum_{t=1}^{T} \gamma_{n g} F_{n g}(t)+\varphi E_{\text {buy }}(t)
\end{gathered}
$$

wherein $t$ is the index for time, and $T$ is the total operating time. $f_{1}, f_{2}$, and $f_{3}$ are the objective functions of the systems of ER, TOC, and CE, respectively.

\subsection{Constraint Conditions}

In the CCHP system, the main constraints of the system are energy balance constraints, gas-steam combined cycle constraints, solar heater collector constraints, power source output constraints, and other module constraints.

\subsubsection{Energy Balance Constraints}

(1) Electricity balance

$$
\begin{gathered}
\left(E_{G T}(t)+E_{W P P}(t)\right) \cdot(1-e)=E_{R E}(t)+E_{E C}(t)+E_{g}(t)+E_{G S H P}(t)+E_{A M}(t) \\
E_{g}(t)+E_{\text {grid }}(t)=E_{\text {load }}(t)
\end{gathered}
$$

wherein $E_{G T}(t)$ is the power generation output of the gas turbine at time $t ; E_{S T}(t)$ is the power generation output of the steam turbine at time $t ; E_{W P P}(t)$ is the wind power output at time $t ; e$ is the station service power consumption ratio of the CCHP system; $E_{R E}(t)$ is the electricity for regenerative electric boiler (RE) at time $t ; E_{E C}(t)$ is the electricity for the electric compression chiller (EC) at time $t ; E_{g}(t)$ is the total electricity at time $t ; E_{\text {load }}(t)$ is the power load required by the buildings at time $t ; E_{\text {grid }}(t)$ is the electricity bought from the grid at time $t ; E_{G S H P}(t)$ is the power required by the ground-source heat pump unit; $E_{A M}(t)$ is the power required for the hot water heat absorption heat pump unit (AM).

(2) Heating balance

$$
\begin{gathered}
Q_{S T, h}(t)+Q_{p v, h}(t)+Q_{G S H P}(t)+Q_{A M, H E}=Q_{h, A C}(t)+Q_{h, H E}(t) \\
Q_{H R, H W}(t)=Q_{H R, A C}(t)+Q_{H R, H E}(t)
\end{gathered}
$$




$$
\begin{gathered}
Q_{H R, A C}(t) \cdot Q_{H R, H E}(t)=0 \\
Q_{H E, h}(t) \geq Q_{h, \text { load }}(t)
\end{gathered}
$$

wherein $Q_{S T, h}(t)$ is the heat energy generated by storage tank (ST) at time $t ; Q_{p v, h}(t)$ is the heat energy generated by regenerative electric boiler (RE); $Q_{G S H P}(t)$ is the heat energy generated by regenerative electric boiler (GSHP) at time $t ; Q_{h, A C}(t)$ and $Q_{h, H E}(t)$ are the heating energies for the absorption chiller (AC) and heat exchanger (HE) at time $t ; Q_{A M}(t)$ is the heat energy generated by $A M$ at time $t ; Q_{H R, A C}(t)$ and $Q_{H R, H E}(t)$ are the heating energies for absorption chiller (AC) and heat exchanger (HE) at time $t ; Q_{H E, h}(t)$ is the heating load provided by HE at time $t ; Q_{h, l o a d}(t)$ is the heating energy load required by the buildings at time $t$.

(3) Cooling balance

$$
Q_{A C, c}(t)+Q_{E C, c}(t) \geq Q_{c, l o a d}(t)
$$

wherein $Q_{A C, c}(t)$ and $Q_{E C, c}(t)$ are the cooling energies generated by electric compression chiller (EC) and absorption chiller (AC)at time $t ; Q_{c, l o a d}(t)$ is the cooling energy load required by the buildings at time $t$.

\subsubsection{Gas-Steam Combined Cycle Constraints}

The gas-steam combined cycle includes gas turbine (GT), storage tank (ST), and heat recovery steam generators (HRSGs), which should meet the constraint conditions of the gas turbine module, HRSG module, and steam turbine module.

The gas turbine module should meet the power generation constraint, gas consumption constraint, and high-temperature fuel gas constraint, as calculated in Equation (18):

$$
Q_{f g}(t)=\frac{E_{G T}(t) \cdot\left(1-\eta_{e l, G T}-\eta_{l o s s, G T}\right)}{\eta_{e l, G T}}
$$

The amount of waste heat recovery is the difference between the consumption of natural gas and the electric energy produced by a gas generator. It is multiplied by the efficiency of the waste heat recovery, as calculated in Equation (19):

$$
Q_{H R}=\left(F_{G T}-E_{G T}\right) \eta_{H R}=F_{G T}\left(1-\eta_{G T} \eta_{E}\right) \eta_{H R}
$$

wherein $Q_{H R}$ is the heat energy generated by HRSGs for storage tank (ST); $\eta_{H R}$ is the heat energy efficiency of HRSGs; $\eta_{G T}$ is the energy efficiency of the gas turbine unit; $\eta_{E}$ is the electricity generation efficiency of the gas turbine unit.

\subsubsection{Auxiliary Subsystem Constraints}

(1) Solar heater collector module

The flat-plate collector is used to collect solar radiation for satisfying the thermal demand. The thermal storage tank is employed as a reserve thermal source for meeting the thermal demand when the solar radiation is insufficient. The equations of the solar collector subsystem model are defined as:

$$
\begin{gathered}
Q_{S C}(t)=F_{\text {Solar }}(t) \cdot \eta_{\text {Solar }, S C} \\
Q_{S C}(t)=Q_{S C, \text { in }}(t)+Q_{S C, H E}(t)
\end{gathered}
$$

wherein $Q_{S C}(t)$ is the heat collected by the flat-plate collector at time $t ; \eta_{S o l a r, S C}$ is the heat conversion efficiency of the flat-plate collector at time $t ; Q_{S C, i n}(t)$ and $Q_{S C, H E}(t)$ are the heat energies generated by Solar heat collector (SC) for storage tank (ST) and heat exchanger (HE) at time $t$. 
(2) Storage tank module

A water storage tank is selected as the buffer between the solar collector and the CCHP subsystem. Assume that the tank is insulated, and the water is well mixed. This will make the temperature of the water in the tank only related to time. Equation (22) expresses the energy balance in SK:

$$
\rho \times C_{P}\left(V_{w}(t)+V_{k}(t)\right) \frac{d T_{L}}{d t}=Q_{S C, \text { in }}(t)+Q_{H R, \text { in }}(t)-Q_{S K, \text { out }}(t)-U_{k} A_{k}\left(T_{L}-T_{a}\right)
$$

wherein $Q_{S K, \text { out }}(t)$ is the heat energy stored by storage tank (ST) at time $t ; Q_{S C, \text { in }}(t), Q_{H R, \text { in }}(t)$ are the heat energies generated by Solar heat collector (SC) and heat recovery steam generator (HR) for storage $\operatorname{tank}(\mathrm{ST})$ at time $t ; \rho$ is the density of the water in the tank; $C_{p}$ is the specific heat at constant pressure; $V_{w}(t), V_{k}(t)$ are the volumes of water in the tank and the tank at time $t ; T_{L}(t)$ is the temperature function of the water in the tank at time $t ; T_{a}(t)$ is the ambient temperature at time $t ; U_{k}$ is the heat transporting coefficient of the water tank; $A_{k}$ is the area of the water tank.

(3) RE operation constraints

The regenerative electric boiler runs to meet the thermal demand during the valley period. When the electric boiler stops running, the hot water in the accumulator is used to provide heat to users during the peak period, as calculated in Equation (23):

$$
Q_{R E}(t)=(1-\mu) Q_{R E}(t-1)\left[E_{R E, \text { in }}(t) \lambda_{R E, \text { in }}(t)-\frac{E_{R E, \text { out }}(t)}{\lambda_{R E, \text { out }}(t)}\right] \Delta t
$$

wherein $Q_{R E}(t)$ is the capacity stored by regenerative electric boiler (RE) at time $t$; $\mu$ is the dissipating heat efficiency of regenerative electric boiler $(\mathrm{RE}) ; E_{R E \text {,in }}(t)$ is the heat energy stored by regenerative electric boiler (RE)at time $t ; E_{R E, \text { out }}(t)$ is the heat energy released by regenerative electric boiler (RE) at time $t ; \lambda_{R E, i n}(t)$ is the stored heat energy efficiency of regenerative electric boiler (RE) at time $t$; $\lambda_{R E, \text { out }}(t)$ is the released heat energy efficiency of regenerative electric boiler (RE) at time $t$.

\subsubsection{Power Source Output Constraints}

Compared with the reference system, the wind power generation output constraint is as follows:

$$
0 \leq E_{W P P, E}(t)+E_{W P P, R}(t)+E_{W P P, \mathrm{ex}}(t) \leq F_{W P P}(t)
$$

wherein $E_{W P P, E}(t)$ is the electricity generated by Wind Power Plant (WPP) for meeting the electricity demand; $E_{W P P, R}(t)$ is the output generated by Wind Power Plant (WPP) for regenerative electric boiler (RE) at time $t ; F_{W P P}(t)$ is the electricity generated by Wind Power Plant (WPP) for regenerative electric boiler (RE) at time $t$.

\subsubsection{Other Module Constraints}

(1) Ground-source heat pump constraints

The cool energy generated by the ground-source heat pump (GSHP), as calculated in Equation (25).

$$
Q_{G S H P, c}=E_{G S H P, c} C O P_{G S H P, c}
$$

wherein $Q_{G S H P, c}$ is the cool energy generated by GSHP at time $t ; E_{G S H P, c}$ is the power consumption by GSHP at time $t ; C_{G S H P, c}$ is the transporting efficiency of the cool energy generated by GSHP.

The heat energy generated by GSHP, as calculated in Equation (26).

$$
Q_{G S H P, h}(t)=E_{G S H P, h}(t) C O P_{G S H P, h}
$$


wherein $Q_{G S H P, h}$ is the heat energy generated by GSHP at time $t ; E_{G S H P, h}$ is the power consumption by GSHP at time $t ; C_{G S H P, h}$ is the transporting efficiency of the heat energy generated by GSHP.

(2) Storage tank constraints

The cool energy released by the storage tank is stored in the ground-source heat pump unit during the valley period, as calculated in Equation (27):

$$
Q_{S T, c}=\sum_{t=1}^{T} Q_{G S T P, C}
$$

wherein $Q_{S T, c}$ is the cool energy released by storage tank (ST).

The heat energy released by the storage tank is stored in the ground-source heat pump unit during the valley period, is calculated in Equation (28):

$$
Q_{S T, h}=\sum_{t=1}^{T} Q_{G S T P, h}
$$

wherein $Q_{S T, h}$ is the heat energy released by storage tank (ST).

The other modules of the GSHP CCHP system include the electric compression chiller, the absorption chillers, and the heat exchangers.

The heat energy generated by the heat exchangers is calculated as follows:

$$
Q_{H E, h}(t)=\left(Q_{H R, H E}(t)+Q_{S C, H E}(t)+Q_{h, H E}(t)+Q_{R E, h}(t)\right) \cdot \eta_{H E}
$$

wherein $Q_{H E, h}(t)$ is the heat energy generated by heat exchanger (HE) at time $t ; Q_{H R, H E}(t)$ is the high-pressure steam provided by heat recovery steam generator (HRSGs) for heat exchanger (HE) at time $t ; Q_{S C, H E}(t), Q_{h, H E}(t)$ are the heat energy flows generated by SC and other components for heat exchanger (HE) at time $t ; \eta_{H E}$ is transporting efficiency of heat exchanger (HE) at time $t$.

The cooling energy generated by the absorption chillers is calculated as:

$$
Q_{A C, C}(t)=\left(Q_{H R, A C}(t)+Q_{h, A C}(t)\right) \cdot C O P_{A C}
$$

wherein $Q_{A C, c}(t)$ is the cooling energy generated by absorption chiller (AC) at time $t ; Q_{H R, A C}(t)$ is the heat medium water flow provided by HRSGs for absorption chiller (AC) at time $t ; Q_{h, A C}(t)$ is generated by other components for absorption chiller (AC); $C O P_{A C}$ is the cooling transporting coefficient of absorption chiller (AC).

The cooling energy generated by the electric compression chillers is calculated as:

$$
Q_{E C, c}(t)=E_{E C}(t) \cdot C O P_{E C}
$$

wherein $Q_{E C, c}(t)$ is the cooling energy generated by electric compression chiller $(E C)$ at time $t ; E_{E C}(t)$ is the electrical energy for electric compression chiller $(\mathrm{EC})$ at time $t ; C O P_{E C}$ is the cooling transporting coefficient of electric compression chiller (EC).

\subsection{Solution Methodology}

\subsubsection{Wind Power Output Uncertainty Set}

In this paper, $g_{w}^{t}$ is the output range of wind power at time $t$. The defining formula is as follows:

$$
g_{w, k}^{d} \leq g_{w, k} \leq g_{w, k}^{u}
$$


In this paper, the absolute predictive error of wind and photovoltaic power is constrained by the 1-norm, and the parameter $\Gamma$ is the uncertainty coefficient.

$$
\sum_{k=1}^{K} \frac{\left|g_{w}^{a}-g_{w}^{f}\right|}{g_{w}^{f}} \leq \Gamma_{1}
$$

wherein $\Gamma_{1}$ is the uncertainty coefficient of wind power output. The specific process of robust optimization is shown in reference [23]. According to the robust optimization theory, the constraint (33) introduces the robust coefficient $\Gamma_{1}$. Changing the value of $\Gamma_{1}$ can adjust the probability level of the solution against the uncertainty parameter constraint. The value range of the random variable in the constraint $i$ has a set relationship with the robust coefficient $\Gamma_{1}$.

\subsubsection{Basic Particle Swarm Optimization Algorithm}

Particle Swarm Optimization (PSO) is a typical swarm intelligence optimization algorithm. Its main principle is that sharing information and collaborating among individuals directs the group to the optimal solution.

In the basic particle swarm optimization algorithm, assume that the total number of particles in the group is $N$, each particle searches at a certain speed in n-dimensional space, the speed of particle $i$ is $V_{i}=\left(v_{i 1}, v_{i 2}, \cdots, v_{i n}\right)$, the current location of particle $i$ is $X_{i}=\left(x_{i 1}, x_{i 2}, \cdots, x_{i n}\right)$, the optimal location of particle $i$ is pbest $t_{i}=\left(p_{i 1}, p_{i 2}, \cdots, p_{i n}\right)$, the global optimal location is gbest $_{i}=\left(g_{i 1}, g_{i 2}, \cdots, g_{i n}\right)$. The speed and flight location of particle will be adjusted according to the individual and group flight experience. The defining formula is as follows:

$$
\begin{gathered}
v_{i j}(t+1)=\omega v_{i j}(t)+c_{1} r_{1}\left(p_{i j}(t)-x_{i j}(t)\right)+c_{2} r_{2}\left(g_{j}(t)-x_{i j}(t)\right) \\
x_{i j}(t+1)=x_{i j}(t)+v_{i j}(t+1)
\end{gathered}
$$

wherein $\omega$ is the inertia weight, $\omega \geq 0 ; c_{1}$ and $c_{2}$ are acceleration factors; $r_{1}$ and $r_{2}$ are random numbers in the range of $(0,1]$. The flow of the basic particle swarm algorithm is as follows.

(1) Parameter initialization. Initialize the particle population size $N$, the acceleration factors $c_{1}$ and $c_{2}$, the maximum particle velocity $v_{\max }$, the maximum iteration number $T$, and so on. Initialize the speed and location of all particles. The initial location of the particle is set as the optimal location, and the initial particle global optimal location is set as the population optimal location.

(2) Update the velocity and location of the particle according to Formulas (34) and (35);

(3) Update the individual optimal location;

(4) Update the particle population optimal location;

(5) Check the terminating condition. If it is satisfied, the algorithm finishes; if not, return to step (2).

\subsubsection{Multi-Objective Particle Swarm Optimization Algorithm}

In the multi-objective optimization problem, each optimization goal may be mutually contradictory. The algorithm must concentrate on non-dominant solution sets and the particle flight direction problem.

(1) Setting up initial parameters

In the process of multi-objective optimization, the common maintenance method for each generation of non-dominant solutions is the initial parameter. The principle underlying the solutions entering initial parameter is that the feasible solution is not dominated by any solution; the feasible solution can dominate the existing solution, and then the solution enters the next step and deletes the dominating solution. 
(2) Optimal particle selection

In the multi-objective optimization problem, the optimal solutions maintained in the external files are non-dominant. In this study, an evaluation method based on nearest-neighbor density is used to find the individual and the global optimal particle.

The crowding distance of each particle is defined in a viable domain: sorting the particles by a target function, the crowding distance of particle $i$ is the distance between particle $i-1$ and particle $i+1$ in the two target functions, as calculated in Equation (36):

$$
\operatorname{dist}[i]=\sum_{j=1}^{n} a b s\left(f_{i+1}^{j}-f_{i-1}^{j}\right)
$$

The larger the crowding distance obtained by Formula (36) is, the smaller the degree of particle crowding is, and the higher the priority of the particle selected as optimal is.

4.3.4. Improvement of the PSO Algorithm Based on the Dynamic Object Method (DOM) Constraint Mechanism

In this paper, the complex constraint processing mechanism-the dynamic object method-is introduced into the basic particle swarm optimization algorithm, which is applied to the robust scheduling multi-objective functions and the corresponding solutions.

The DOM constraint mechanism transforms the constraint condition into a new target function by $\phi(X)$. For an optimization model with $p$ inequality constraints and $q$ equality constraints:

$$
\begin{gathered}
\min F(X) \\
\text { s.t. }\left\{\begin{array}{l}
g_{i}(X) \leq 0, i=1,2, \cdots, p \\
h_{j}(X)=0, j=1,2, \cdots, q
\end{array}\right.
\end{gathered}
$$

The distance function corresponding to the constraint condition has the following defining formula:

$$
\phi(X)=\sum_{i=1}^{p} \max \left\{0, g_{i}(X)\right\}+\sum_{j=1}^{q}\left\{0,\left|h_{j}(X)\right|-\varepsilon\right\}
$$

wherein $\varepsilon$ is an arbitrary positive number and, according to the actual algorithm requirements, $\varepsilon=0.00001$. The new optimization is calculated as Equation (39):

$$
\min (\phi(X), F(X))
$$

If the particle is not in the scope of the feasible domain, $\phi(X)$ is used as the optimization target, which brings the particles close to the scope of the feasible region. When $\phi(X)=0$ or $\phi(X) \leq \delta$ is within the constraint's permissible error (usually a very small positive number; in this paper, $\delta=0.1$ ), the particle swarm optimizes the object $F(X)$. As a particle departs from the feasible region, the optimization object of the particle returns to $\phi(X)$. Through the dynamic adjustment of the optimized object, the particle can find the optimal solution within the feasible region's scope. In the iterative process, the particle can calculate object, and the efficiency of the algorithm is improved. The overall flow of the improved PSO multi-objective optimization algorithm based on the DOM constraint mechanism is shown in Figure 2. 


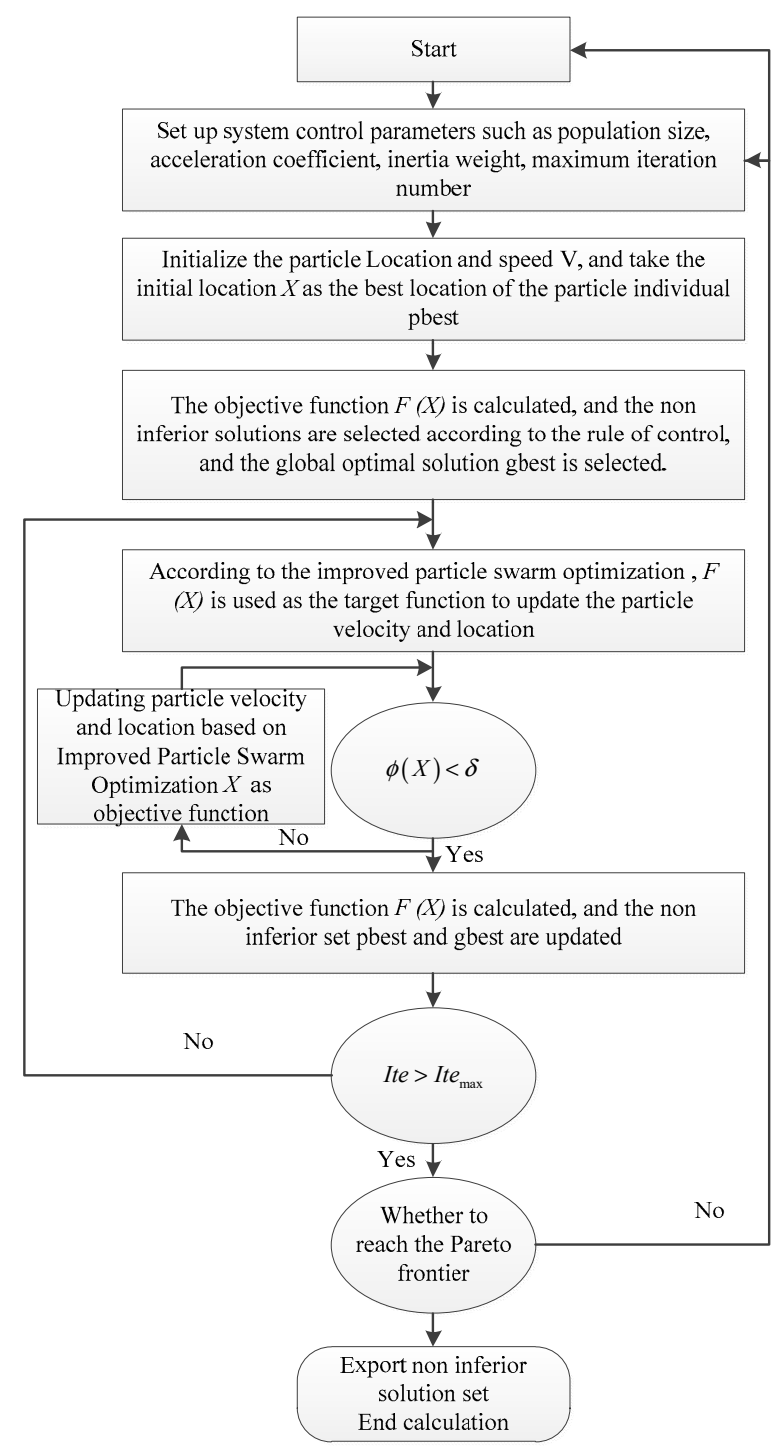

Figure 2. Flowchart of improved particle swarm optimization based on dynamic object method (DOM) constraint mechanism.

\section{Example Analysis}

\subsection{Basic Data}

Set the population size to 50 , the maximum number of generations is 200 , the inertia weights are linearly decreasing weights, the maximum and minimum values are 0.9 and 0.4 respectively, the learning is 2 , the variation is 10 , and the longitudinal cross probability is 0.6 .

The system investment includes the gas turbine unit, flue gas hot water absorption heat pump unit, ground-source heat pump unit, electric refrigeration steam compression refrigeration unit, energy storage tank, and other auxiliary equipment. The estimate of the investment is shown in Table 1.

Table 1. System investment estimate.

\begin{tabular}{cc}
\hline No. & Amount (10,000 yuan) \\
\hline Engineering fee & 4865 \\
Other expenses & 654 \\
Interest & 125 \\
\hline
\end{tabular}


Table 2 shows the price list of the auxiliary materials. The electricity price in the table is the non-resident electricity price in Tianjin.

Table 2. System auxiliary material prices.

\begin{tabular}{cc}
\hline Type & Price \\
\hline Natural gas & 2.4 yuan $/ \mathrm{m}^{3}$ \\
Electricity & $1.2863 / 0.8293 / 0.3351$ yuan $/ \mathrm{kW} \cdot \mathrm{h}$ \\
Water & 5.6 yuan $/$ ton \\
\hline
\end{tabular}

The rated power of the gas turbine is $80 \mathrm{MW}$, the capacity of the power generator in Tianjin Eco-City is $30 \mathrm{MW}$, the power of the ground-source heat pump unit is $3.55 \mathrm{MW}$, the heating power is $4.1 \mathrm{MW}$, and the power of the electric refrigeration steam compression refrigeration unit is $4.1 \mathrm{MW}$. The parameter of the flue gas hot water absorption heat pump unit is $20 \mathrm{MW}$, and the heat power is $22 \mathrm{MW}$. The rated power of the storage tank is $72 \mathrm{MW}$. Figure 3 is the wind turbine power output curve.

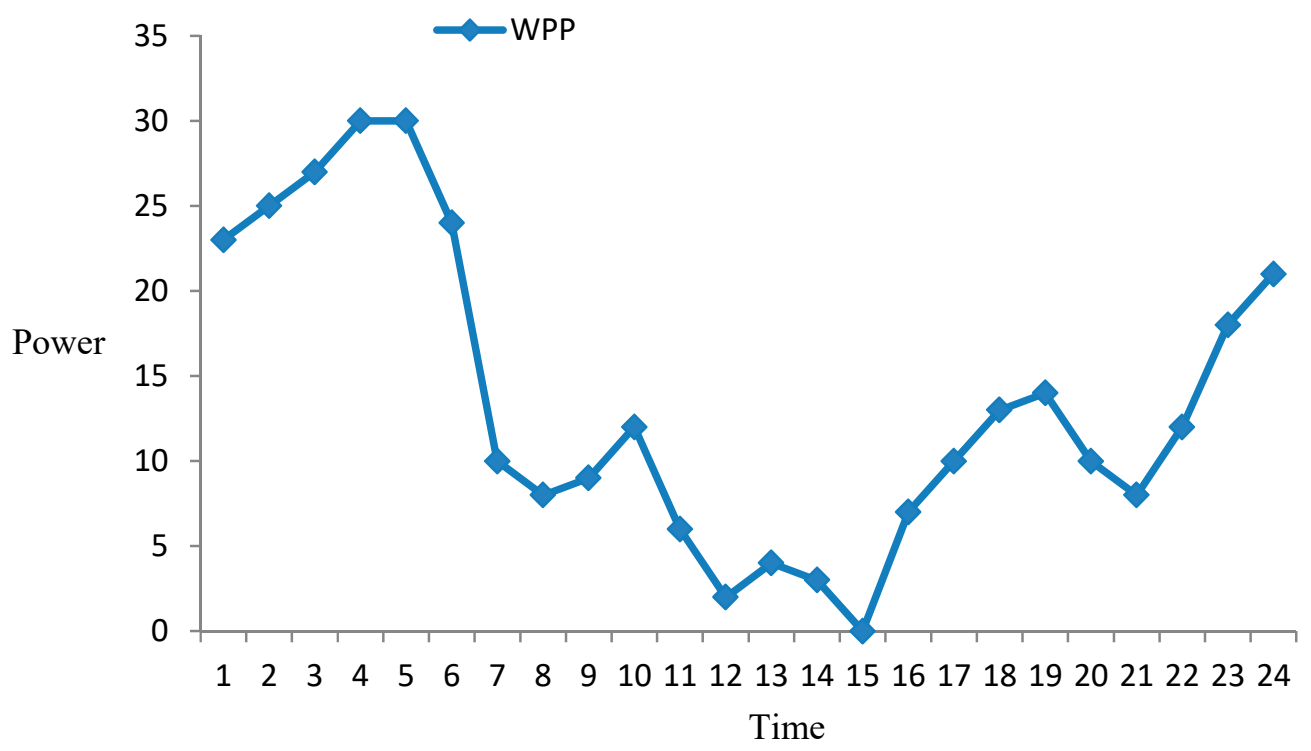

Figure 3. Wind turbine power output curve.

To meet system scheduling requirements, the regression and prediction of wind speed and photothermal intensity are needed; these functions are calculated based on historical data. As the aim of this paper is to analyze the economic benefits of the system, the methods of measuring wind speed and photovoltaic energy are not discussed. Instead, the annual average wind speed and photothermal intensity are chosen as input data. Figure 4 shows the average hourly electric, cooling, and heating load demands for Tianjin Eco-City. 


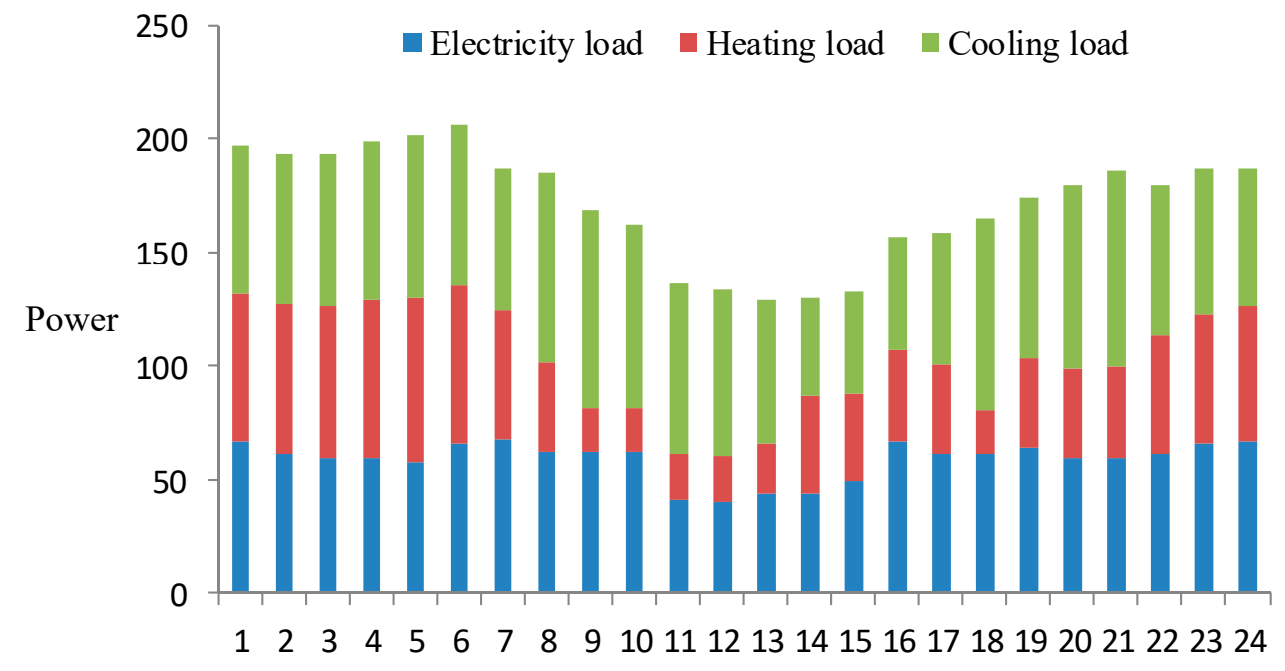

Time

Figure 4. Average hourly electric, cooling, and heating load demands for Tianjin Eco-City (unit: MW).

\subsection{Operation Results with Signal Objective}

\subsubsection{Operation Result in Scenario 1}

For the traditional PSO algorithm, the group particles are updated in the solution space, some particles search nearby value areas, which speeds up the local update; the other particles search at a location far from the current optimal value to ensure the diversity of the population and make up for the PSO algorithm. The PSO algorithm is easy to fall into the local minimum. It is widely used in solving spatial search problems and can obtain efficient optimization simulation results. After the 50th iteration, the energy variation diagrams of different structures of the system with different robust coefficients are obtained.

The different scenarios (scenarios 1-5) in Table 3 correspond to different risk preferences of the decision-maker for each scenario. With the increase of the robust control coefficient, the probability of a constraint violation of the uncertainty coefficient of the virtual power plant decreases gradually, and the probability of a chance constraint violation is also reduced.

Table 3. Optimization results under different constraint violation probabilities.

\begin{tabular}{ccc}
\hline Scenario & $\Gamma$ & Constraint Violation Probability \\
\hline 1 & 0 & 53.64 \\
2 & 1 & 50 \\
3 & 3 & 41.36 \\
4 & 5 & 33.13 \\
5 & 12 & 11.5 \\
\hline
\end{tabular}

In scenario $1, \Gamma=0$, and the violation probability is 0.5364 ; the results of system optimization are shown in Figure 5. 

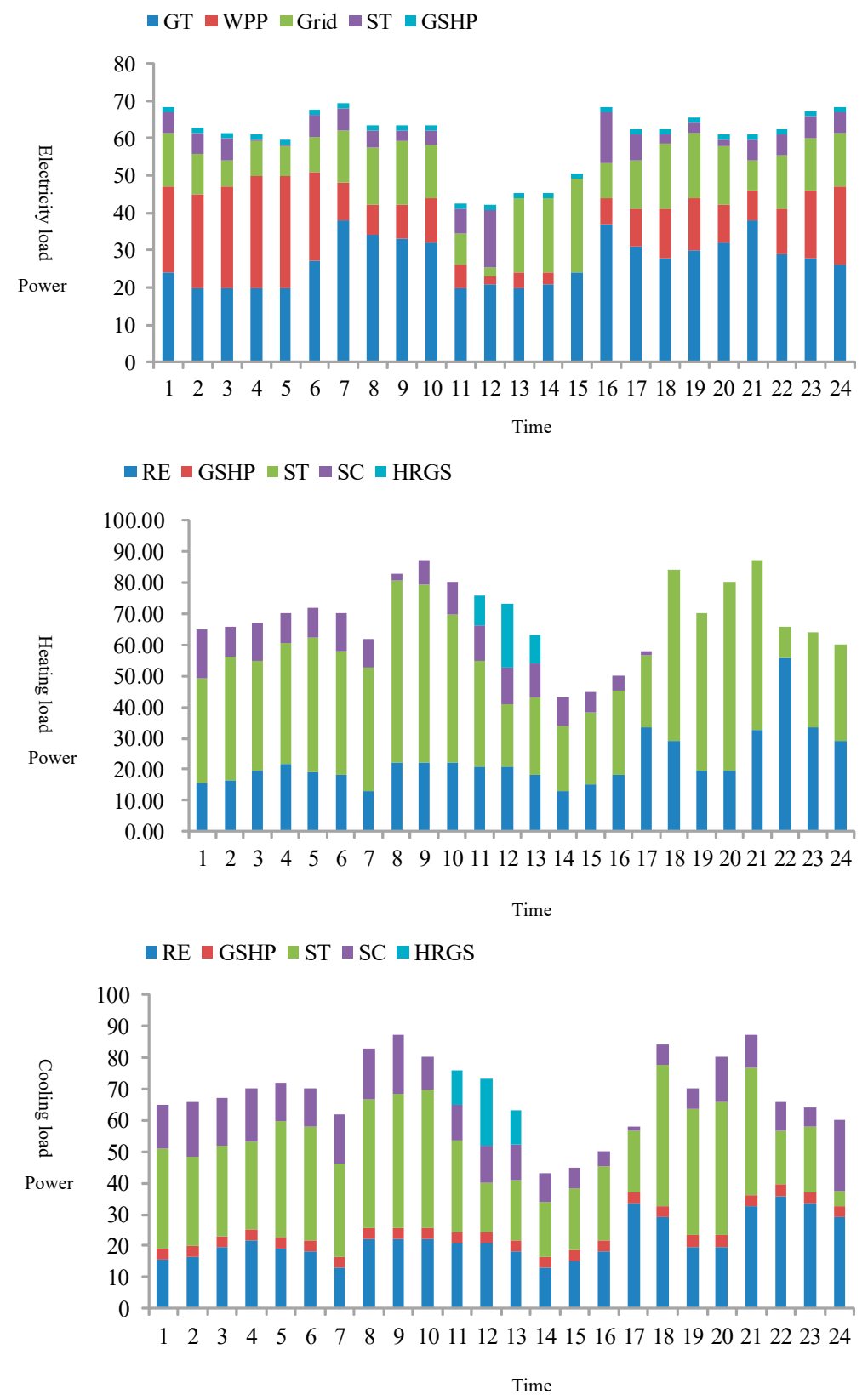

Figure 5. Hourly electric, heating, and cooling load supply of scenario 1 (unit: MW).

In scenario 1, the decision model considers the multi-objective benefits of the system without the influence of the wind power uncertainty on the system. The system does not schedule the demand side or supply side resources to eliminate the impact of wind power output randomness. Compared with load consumption of the non-optimized system, the optimized system schedule transfers the load consumption from the peak price period to the flat period.

\subsubsection{Operation Results in Scenario 2}

In scenario $2, \Gamma=1$, and the violation probability is 0.5 ; the results of system optimization are shown in Figure 6. 

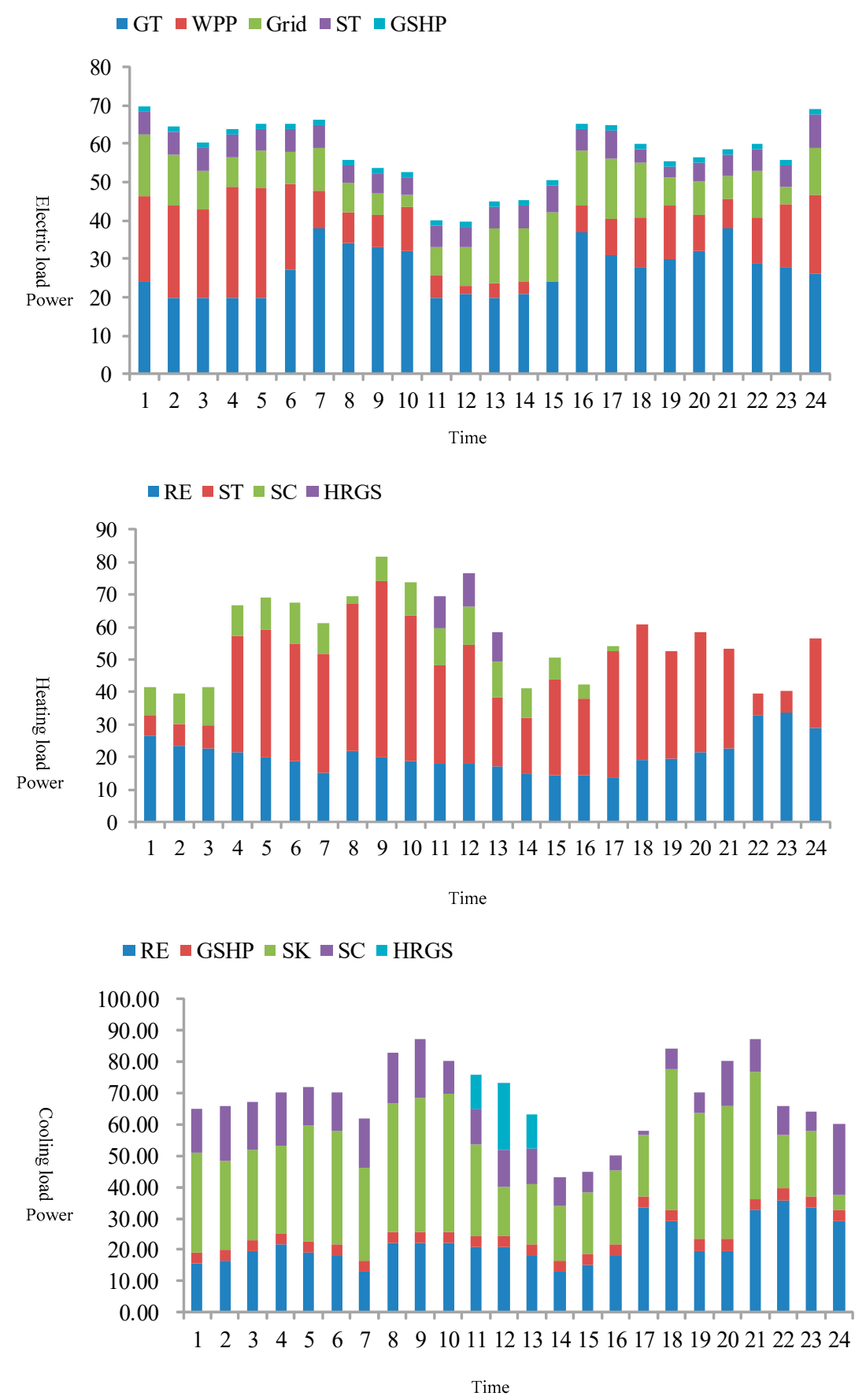

Figure 6. Hourly electric, heating, and cooling load supply of scenario 2 (unit: MW).

The optimization method, considering the uncertainty disturbance, will dispatch the energy storage tank and the CCHP output power to eliminate the power imbalance caused by the uncertainty. Compared with Figure 6, the energy storage tank curve shows that the change in the storage state of charge (SOC) of the accumulator is the result of charging during the valley period and discharging during the peak period. Compared with the depth of the released energy, the random disturbance occurs in the 6:00-19:00 period, so the SOC of the accumulator tank in Figure 6 is lower in 11:00-18:00 period. 


\subsubsection{Operation Results in Scenario 3}

In scenario $3, \Gamma=3$, and the violation probability is 0.4136 ; the results of system optimization are shown in Figure 7.
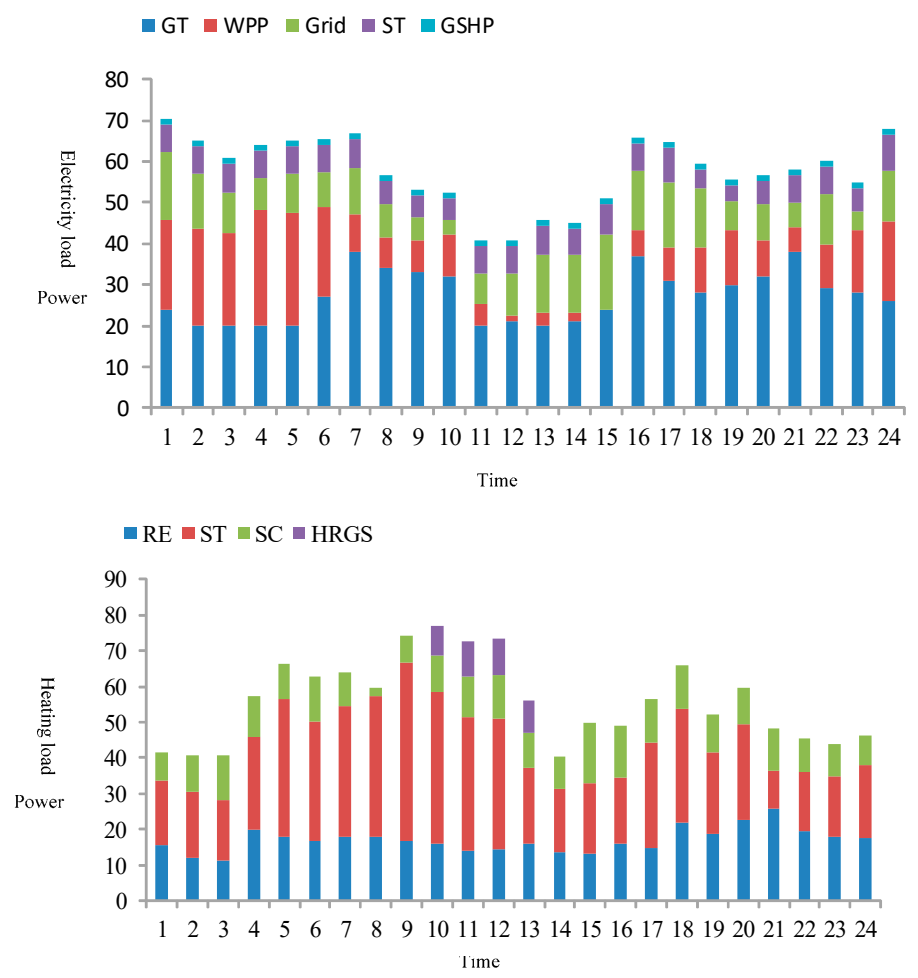

$\square \mathrm{RE} \backsim \mathrm{GSHP} \backsim \mathrm{ST} \backsim \mathrm{SC} \backsim \mathrm{HRGS}$

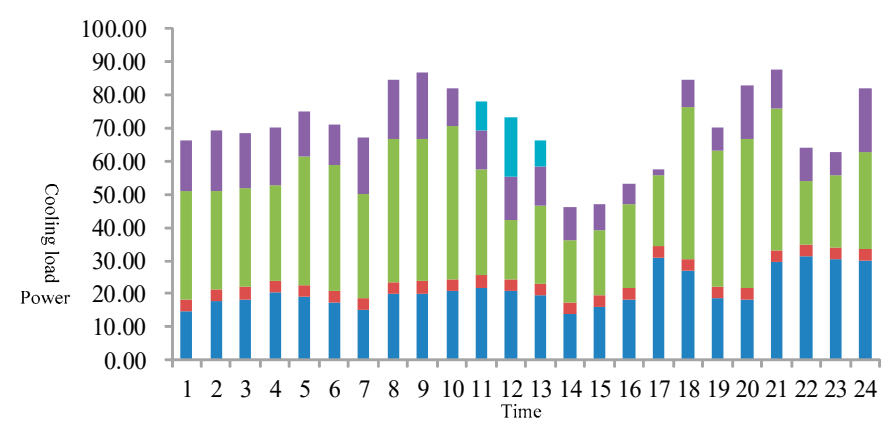

Figure 7. Hourly electric, heating, and cooling load supply of scenario 3 (unit: MW).

In Figures 5 and 6, the charging and discharging trend of the battery in the two diagrams is consistent, but the energy storage tank in Figure 7 has a lower energy releasing depth. Because of the high price of natural gas, Figure 7 shows an increase in the power supply of the grid and the ground-source heat pump, thus reducing the energy supply of the CCHP. To obtain a greater economic benefit, the energy storage tank charges in the peak period of 18:00-23:00 and discharges in the 11:00-18:00 period.

\subsubsection{Operation Result in Scenario 4}

In scenario $4, \Gamma=5$, and the violation probability is 0.3313 ; the results of system optimization are shown in Figure 8. 


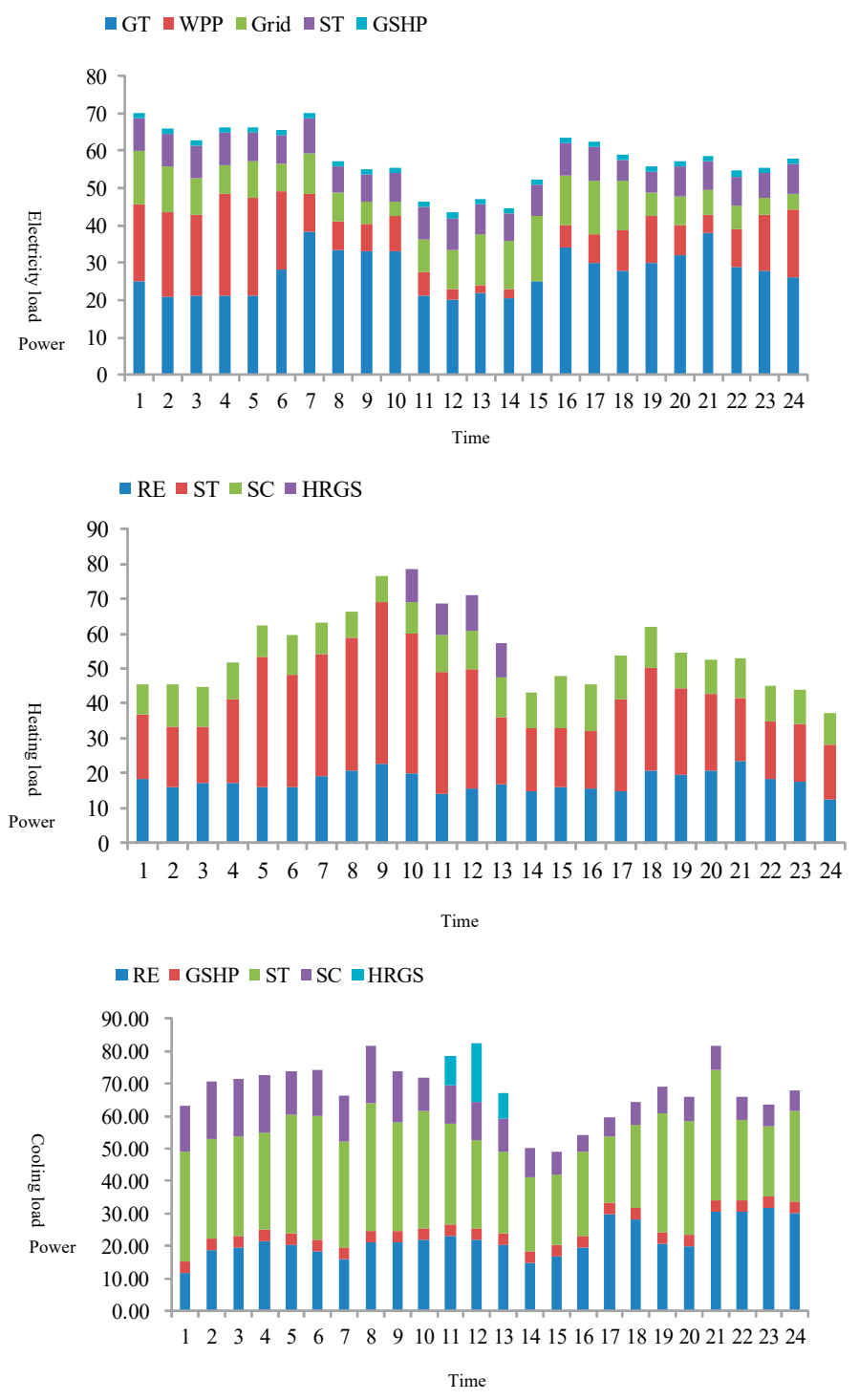

Figure 8. Hourly electric, heating, and cooling load supply of scenario 4 (unit: MW).

With the increased $\Gamma$, the uncertainty in the constraint is close to the worst, and the wind power output may be lower or the load demand higher. As shown in Figure 8, the power output of the gas turbine unit increases in response to the increased uncertainty, and the system schedules more energy supply and load resources to deal with the power imbalance, which causes the system's operating costs and carbon emissions to increase.

\subsubsection{Operation Result in Scenario 5}

In scenario $5, \Gamma=12$, and the violation probability is 0.115 ; the results of system optimization are shown in Figure 9. 

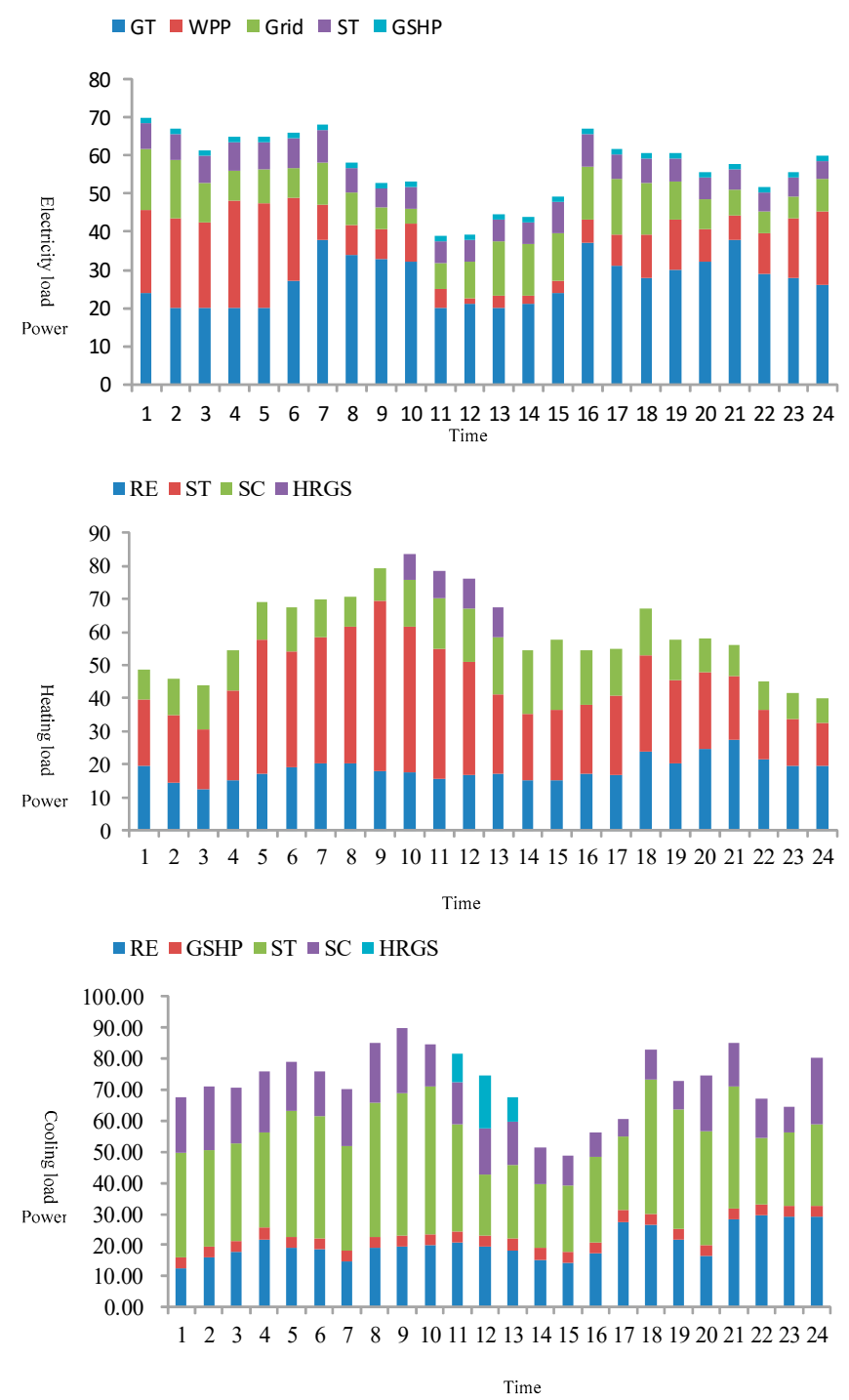

Figure 9. Hourly electric, heating, and cooling load supply of scenario 5 (unit: MW).

In Figure 9, all power supplies are evenly distributed, and the energy storage tank does not work. Although the optimal cost and optimal carbon emissions are obtained, the scheduling method can easily lead to excessive reliance on some power sources, thus affecting the comprehensive operation benefit of the system. Therefore, by implementing the scheduling method proposed in this paper, decision-makers can get diverse solutions to coordinate the economic and environmental benefits of the system operation and ensure that the power supplies are balanced.

By simulating the optimization algorithm, the improved PSO algorithm can effectively reduce the network loss, wind power output deviation and system operation cost. The algorithm converges quickly and effectively avoids premature convergence and can jump out of the local minimum in time. It shows that the algorithm changes the update strategy of the global optimal solution and improves the global search efficiency.

\subsection{Evaluation and Comparison of the Different Scenarios}

This subsection presents the evaluation results of the distributed energy resource (DER) CCHP system considering the energy performance, economic performance, and environmental performance. Table 4 lists the annual ER, TOC, CER, NPV, and IRR values of the different scenarios. For the energy performance in Scenarios 1-5, as the robust control coefficient increases, the probability of constraint violation of the uncertainty coefficient decreases gradually, and the ER of the system also decreases 
gradually. For the economic performance, as the robust control coefficient increases, the TOC of the system also increases gradually. For the environmental performance, as the robust control coefficient increases, the $\mathrm{CE}$ of the system also increases gradually.

Table 4. Annual ER, TOC, CE, NPV, and IRR for different optimization modes.

\begin{tabular}{lccccc}
\hline & ER/\% & TOC/million yuan & $\begin{array}{c}\text { Carbon Dioxide } \\
\text { Emission/1000 ton }\end{array}$ & NPV/million yuan & IRR/\% \\
\hline Scenario 1 & 77.9 & 130.369 & 1677.36 & 32.35 & 9.62 \\
Scenario 2 & 58.6 & 121.415 & 1270.48 & 120.94 & 13.75 \\
Scenario 3 & 72.9 & 128.655 & 1803.74 & 49.67 & 10.45 \\
Scenario 4 & 64.5 & 126.123 & 1384.74 & 74.39 & 11.62 \\
Scenario 5 & 63.3 & 156.756 & 1434.63 & 63.25 & 10.53 \\
\hline
\end{tabular}

Table 4 shows the effect of the value of the uncertainty coefficient on the system power. When the robustness factor is small, the model considers that the energy storage equipment has a small charging load. The electric vehicle user can schedule the discharging time at the system load peak to reduce the load. With the increase of the coefficient, the model considers that the charging load of the energy storage equipment is getting larger and larger, that is, the energy demand is getting larger and larger. To reduce the operating cost, the energy storage equipment can only be charged, so the decision-maker needs to adjust the model according to the actual situation.

\section{Conclusions}

This paper presents the model of a combined cooling, heating, and power system driven by distributed energy resources. The system consists of three subsystems, namely, the electricity subsystem, the CCHP subsystem, and the auxiliary heating subsystem.

An improved particle swarm optimization algorithm is proposed to solve the multi-objective optimization model. To effectively improve the global convergence performance of the particle swarm optimization algorithm, the cross-sectional crossover operator introduces a particle swarm optimization algorithm to maintain the diversity of the population through cross-search; Simultaneously, the calculation speed is improved. The concept of the degree of population agglomeration is introduced, and the vertical crossover is performed when the degree of aggregation of the particles reaches a certain threshold.

Focusing on the optimization problem of the system operation economics under renewable energy uncertainty, a robust operation optimization method based on PSO is proposed, and the proposed method solves the problem of system operation risk caused by multiple uncertain disturbances and the conservative operation problem caused by uncertainties. Furthermore, the model makes it possible to achieve a stable system operation and obtain the best economic benefit. The economic and environmental benefits of the system operation under an uncertain disturbance are improved, and the conservation problem of the operating scheme under a multi-objective framework is addressed. Theoretical support is provided to demonstrate the robustness of the system operation and the optimal comprehensive benefit.

The PSO algorithm and its improvement method are analyzed. Although the PSO algorithm has high efficiency and high stability, it has the disadvantage of being easy to fall into local optimum. In view of this shortcoming, the algorithm is improved, and the proportion of local search and global search is balanced. It is beneficial to jump out of the local optimum. Finally, the improved PSO algorithm is applied to the system optimization operation with Distributed Generation (DG), which provides a new idea for the future optimization of the system with DG.

Author Contributions: Z.T. guided the research; Q.T. and H.G. established the model, implemented the simulation, and wrote this article; S.Y. collected references; L.J., D.G., X.S. and H.L. revised the language of this article.

Funding: Project Supported by National Natural Science Foundation of China (71573084) and Beijing Municipal Social Science Foundation (16JDYJB044). The authors declare no conflict of interest. 
Conflicts of Interest: It should be noted that the whole work was accomplished by the authors collaboratively. All authors read and approved the final manuscript.

\section{Nomenclature}

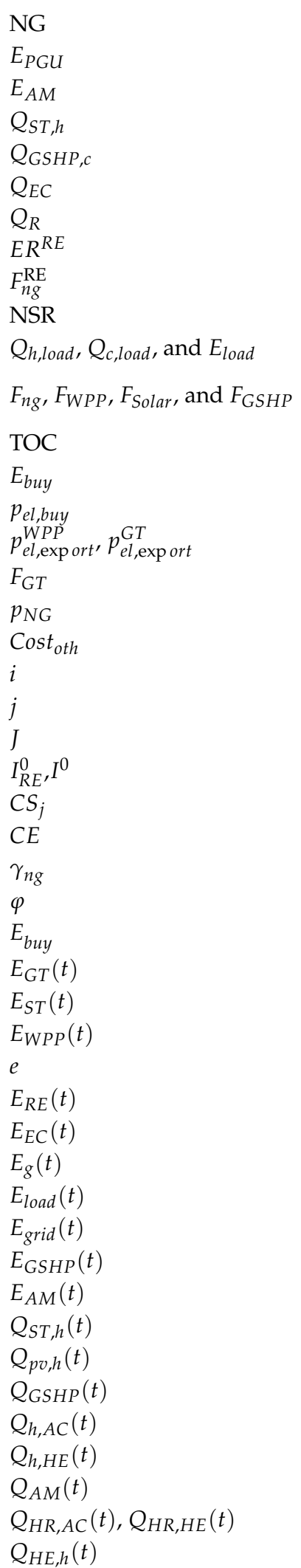

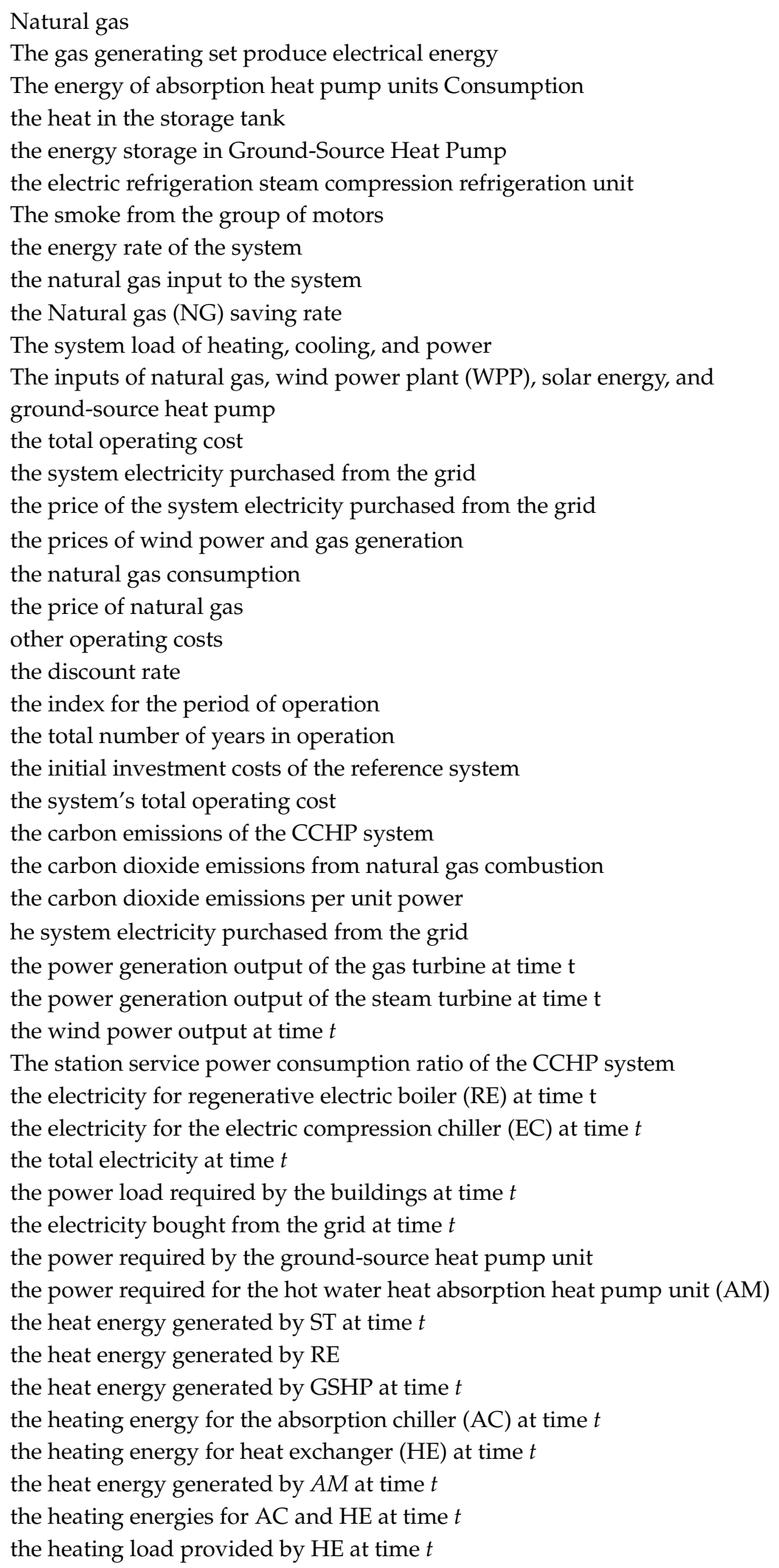




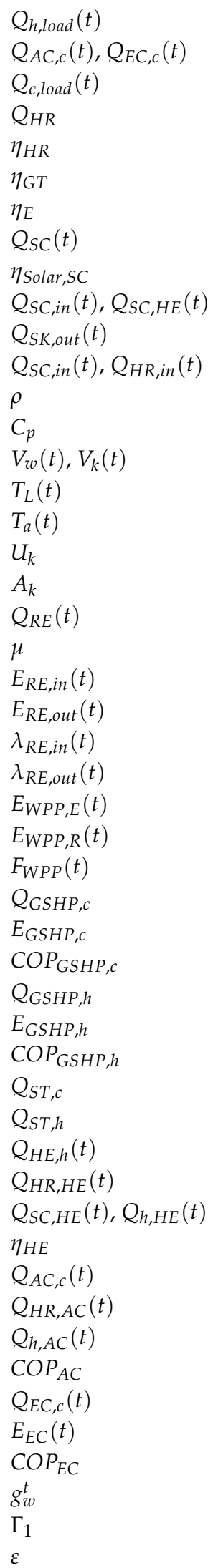

the heating energy load required by the buildings at time $t$ The cooling energies generated by EC and AC at time $t$ the cooling energy load required by the buildings at time $t$ the heat energy generated by HRSGs for ST the heat energy efficiency of HRSGs the energy efficiency of the gas turbine unit the electricity generation efficiency of the gas turbine unit the heat collected by the flat-plate collector at time $t$ The heat conversion efficiency of the flat-plate collector at time $t$ the heat energies generated by SC for ST and HE at time $t$ the heat energy stored by ST at time $t$ the heat energies generated by SC and HR for ST at time $t$ the density of the water in the tank the specific heat at constant pressure the volumes of water in the tank and the tank at time $t$ the temperature function of the water in the tank at time $t$ the ambient temperature at time $t$ the heat transporting coefficient of the water tank the area of the water tank the capacity stored by RE at time $t$ the dissipating heat efficiency of RE the heat energy stored by RE at time $t$ the heat energy released by RE at time $t$ the stored heat energy efficiency of RE at time $t$ the released heat energy efficiency of RE at time $t$ the electricity generated by WPP for meeting the electricity demand the output generated by WPP for RE at time $t$ the electricity generated by WPP for RE at time $t$ the cool energy generated by the GSHP at time $t$ the power consumption by the GSHP at time $t$ the transporting efficiency of the cool energy generated by the GSHP the heat energy generated by the GSHP at time $t$ the power consumption by the GSHP at time $t$ the transporting efficiency of the heat energy generated by the GSHP the cool energy released by ST the heat energy released by ST the heat energy generated by $\mathrm{HE}$ at time $\mathrm{t}$ the high-pressure steam provided by HRSGs for HE at time $t$ the heat energy flows generated by SC and other components for HE at time $t$ transporting efficiency of $\mathrm{HE}$ at time $t$ the cooling energy generated by AC at time $t$ the heat medium water flow provided by HRSGs for AC at time $t$ other components for AC the cooling transporting coefficient of AC the cooling energy generated by EC at time $t$ the electrical energy for EC at time $t$ the cooling transporting coefficient of EC the minimum and maximum output range of wind power at time $t$ the uncertainty coefficient of wind power output an arbitrary positive number 


\section{References}

1. Chen, Q.; Wang, W.; Lu, J.; Ding, J. An overview of the political, technical and economical aspects of gas-fired distributed energy system in China. Appl. Therm. Eng. 2013, 52, 531-537. [CrossRef]

2. Chen, Y.; Cheng, J.J.; Creamer, K.S. Inhibition of anaerobic digestion process: A review. Bioresour. Technol. 2008, 99, 4044-4064. [CrossRef] [PubMed]

3. Midilli, A.; Dogru, M.; Howarth, C.R.; Ling, M.J.; Ayhan, T. Combustible gas production from sewage sludge with a downdraft gasifiery. Energy Convers. Manag. 2001, 42, 157-172. [CrossRef]

4. Zhang, Q.; Wu, Y.; Dor, L.; Yang, W.; Blasiak, W. A thermo dynamic analysis of solid waste gasification in the Plasma Gasification Melting process. Appl. Energy 2013, 112, 405-413. [CrossRef]

5. Wu, D.W.; Wang, R.Z. Combined cooling, heating and power: A review. Prog. Energy Combust. Sci. 2006, 2, 459-495. [CrossRef]

6. Cho, H.; Smith, A.D.; Mago, P. Combined cooling, heating and power: A review of performance improvement and optimization. Appl. Energy 2014, 36, 168-185. [CrossRef]

7. Suamir, I.; Tassou, S. Performance evaluation of integrated trigeneration and $\mathrm{CO}_{2}$ refrigeration systems. Appl. Therm. Eng. 2013, 50, 1487-1495. [CrossRef]

8. Fumo, N.; Chamra, L.M. Analysis of systems based on source primary energy combined cooling, heating, and power consumption. Appl. Energy 2010, 87, 2023-2030. [CrossRef]

9. Wang, J.F.; Zhao, P.; Niu, X.Q.; Dai, Y.P. Parametric analysis of a new combined cooling, heating and power system with transcritical $\mathrm{CO}_{2}$ driven by solar energy. Appl. Energy 2012, 94, 58-64. [CrossRef]

10. Mago, P.J. Performance analysis of CCHP and CHP systems operating following the thermal and electric load. Int. J. Energy Res. 2009, 43, 852-864. [CrossRef]

11. Maraver, D.; Sin, A.; Royo, J.; Sebastián, F. Assessment of CCHP systems based on biomass combustion for small-scale applications through a review of the technology and analysis of energy efficiency parameters. Appl. Energy 2013, 102, 1303-1313. [CrossRef]

12. Gao, P.; Li, W.; Cheng, Y.; Tong, Y.W.; Dai, Y.; Wang, R. Thermodynamic performance assessment of CCHP system driven by different composition gas. Appl. Energy 2014, 136, 599-610. [CrossRef]

13. Li, S.; Sui, J.; Jin, H.; Zheng, J. Full chain energy performance for a combined cooling, heating and power system running with methanol and solar energy. Appl. Energy 2013, 112, 673-681. [CrossRef]

14. Hu, M.Q. A probability constrained multi-objective optimization model for CCHP system operation decision support. Appl. Energy 2014, 116, 230-242. [CrossRef]

15. Cardona, E. Optimal design of CHCP plants in the civil sector by thermo-economics. Appl. Energy 2007, 84, 729-748. [CrossRef]

16. Kong, X.Q.; Wang, R.Z.; Li, Y.; Huang, X.H. Optimal operation of a micro-combined cooling, heating and power system driven by a gas engine. Energy Convers. Manag. 2009, 50, 530-538. [CrossRef]

17. Ren, H.B. A MILP model for integrated plan and evaluation of distributed energy systems. Appl. Energy 2010, 87, 1001-1014. [CrossRef]

18. Chua, K.J.; Yang, W.M.; Er, S.S.; Ho, C.A. Sustainable energy systems for a remote island community. Appl. Energy 2014, 113, 1752-1763. [CrossRef]

19. Flores, R.J. Dynamic distributed generation dispatch strategy for lowering the cost of building energy. Appl. Energy 2014, 132, 196-208. [CrossRef]

20. Li, H.; Fu, L.; Geng, K.; Jiang, Y. Energy utilization evaluation of CCHP systems. Energy Build. 2006, 38, 253-257. [CrossRef]

21. Burdett, R.L.; Kozan, E. A multi-criteria approach for hospital capacity analysis. Eur. J. Oper. Res. 2016, 255, 505-521. [CrossRef]

22. Burdett, R.L. Multi-objective models and techniques for railway capacity analysis. Eur. J. Oper. Res. 2015, 245, 489-505. [CrossRef]

23. Wang, L. Robust Multi-Objective Operation Optimization for Multi-Energy Complementary Microgrids. Ph.D. Thesis, Shandong University, Jinan, China, 2017; pp. 32-36.

(C) 2019 by the authors. Licensee MDPI, Basel, Switzerland. This article is an open access article distributed under the terms and conditions of the Creative Commons Attribution (CC BY) license (http:// creativecommons.org/licenses/by/4.0/). 